\title{
SSO: Access osteotomy for benign pathologies of posterior mandible
}

\author{
Sanchit Jain \\ Senior Lecturer, Hitkarini Dental College \& Hospital, Jabalpur, Madhya Pradesh, India
}

Corresponding Author:

Email: sanchit.ja90@gmail.com

\begin{abstract}
Sagittal split osteotomy has been used to address skeletal deformities involving the mandible. The versatility of the procedure has already been established in the past. This modality has rarely been used as access osteotomy. This article reviews the usage of sagittal split osteotomy for access to various benign pathologies which mainly involves the posterior mandible. The article also discusses various modalities which are used in order to address deeply seated pathologies. The various indications and anatomic consideration for using sagittal split osteotomy along with the advantages of this procedure over other procedures have been discussed.
\end{abstract}

Keywords: Sagittal split osteotomy, Access osteotomy, Bilateral Sagittal Split Osteotomy.

\section{Introduction}

There are various pathologies which commonly affect the mandible in the angle region as well as the posterior body region which are difficult to access. ${ }^{1-3}$ The access to the posterior mandible can we achieved mainly by Sagittal Split Osteotomy (SSO) in those cases where the pathologies are mostly benign and remain the medullary part of mandible like odontoma. Most of the pathologies in the posterior mandible remain unidentified unless they turn painful and attain a larger size which makes it difficult for surgical excision of these lesions.

These are diagnosed incidentally and most of time during routine radiographic examination. Those pathologies which are considered to have very limited potential of growth and not showing active growth during various growth period of life can be accessed by this technique. These are rarely symptomatic and are associated with pain in the region where these are present. $^{4,5}$

The proximity of the IAN has been always been a relative contraindication in removal of any lesion which remains constant with life with no secondary changes. ${ }^{3,6}$ The access to the various pathologies which are located deep in the angle of mandible and in close proximity with the inferior alveolar nerve could be easily accessed by using sagittal split osteotomy of mandible as reported earlier by various authors ${ }^{7,8}$

\section{Discussion}

The sagittal split osteotomy was first was introduced for the removal of large tumor of mandible in 1979 by Rittersema and van Gool. Since then it is considered as one of the methods for the removal of deeply seated lesion of mandible. The factors can broadly be divided in to anatomic factors, access factors, size of the lesion. ${ }^{2,5,9}$

The anatomic factors includes the proximity of the adjacent tooth structures, nerve components such as inferior alveolar nerve. The location of the lesion may be too deep or lingually placed which is one important factor which determines the method of surgical access to the structure. 6,9 There are chances of fracture in cases where the size of the pathology is large and located more close to inferior border requiring more removal of bone for complete enucleation of the lesion.

There are various surgical techniques for the removing large benign lesion of the mandible. They include:

1. Intraoral buccal approach in which the buccal cortical plate is removed and the lesion is adequately exposed before enucleation, ${ }^{9}$

2. Intraoral lingual approach in which the lingual cortical plate is fractured and the lesion is exposed. The care is taken to dissect the flap along with periosteum and keeping the instrument close to bone and prevent any perforation because of the close proximity of the lingual nerve. ${ }^{2,5}$

3. Segmental osteotomy in which extraoral submandibular incision is given and partial segmentation of the bone is done. This procedure generally requires bone grafting. ${ }^{4,5,10,11}$

4. Bony lid technique in which extraoral incision is given and sagittal split of the body of mandible is done to expose the lesion. . $^{5}$

The unilateral sagittal spilt osteotomy along with its modifications another resort of surgical approach to the lesion of the mandible. (Table 1) 
Table 1: List of all authors who have used SSO for treatment of various pathologies in the past

\begin{tabular}{|l|l|c|l|}
\hline S. No. & \multicolumn{1}{|c|}{ Authors } & Year & \multicolumn{1}{|c|}{$\begin{array}{l}\text { Tumors or } \\
\text { Pathology }\end{array}$} \\
\hline 1. & $\begin{array}{l}\text { Rittersma and van } \\
\text { Gool }\end{array}$ & 1979 & Keratocyst \\
\hline 2. & Barnard & 1983 & Odontoma \\
\hline 3. & Frame & 1986 & Odontoma \\
\hline 4. & Petti et al & 1987 & Myxoma \\
\hline 5. & Wong & 1989 & Odontoma \\
\hline 6. & Wong & 1992 & Myxoma \\
\hline 7. & Guven & 1999 & Odontoma \\
\hline 8. & Casap et al & 2006 & Odontoma \\
\hline 9. & Paoli et al & 2007 & $\begin{array}{l}\text { O OKC and 2 } \\
\text { Dentigenous cysts. }\end{array}$ \\
\hline 10. & Orbach et al & 2008 & Ossifying Fibroma \\
\hline 11. & Virendra Singh & 2012 & Unilocular cyst \\
\hline 12. & $\begin{array}{l}\text { Laith Mahmood et } \\
\text { al }\end{array}$ & 2013 & Schwannoma \\
\hline 13. & de Oliveira et al & 2014 & Complex odontoma \\
\hline
\end{tabular}

There are various noted advantages of using the sagittal split osteotomy for the surgical access in deeply placed lesions or lesion which are in close proximity to the inferior alveolar nerve. The sagittal split osteotomy is carried out intraorally thus avoiding external scar and more esthetic when compared to extraoral approach. ${ }^{8,12}$ This also prevents injury to the terminal branches of the facial nerve which could be damaged during the expose to the mandible for osteotomy using extraoral approach. ${ }^{5}$ The SSO can we used to remove lesion which are in tight contact with IAN with adequate and direct visibility of the canal and hence preventing permanent damage to the neural structure. The visibility of the inferior alveolar nerve and canal is diminished in extraoral approach which also makes it a relatively bad option to deal with deeply placed or inferiorly placed lesion of mandible. ${ }^{4,6}$ The is relatively more control of the surgical field in cases of SSO cause various modifications of the SSO can be used which have been described in recent past. ${ }^{4,11,13}$ The lingual approach has more complications which might lead to lingual paraesthesia if the plane is not kept subperiosteally. This is one factor to be considered is the fact that even there is IAN dysfunction after SSO. There is presence of paraesthesia in about 34\% after four days after surgery but that also drastically reduces to about only $8 \%$ after six months. ${ }^{7}$ The fact that the paraesthesia in the lower lip is not too bothersome to the patients makes it very convenient for the patients that the paraesthesia of the lingual tissues.

SSO is technically more difficult than corticotomy but can prevent fracture leading to discontinuity of the mandible during the procedure and hence is preferred more in deeply seated pathologies of the mandible. ${ }^{4,12}$ Corticotomy may hence sometimes be supplemented with grafting procedures to prevent fracture of the mandible after the procedure is completed. ${ }^{5}$ There are various others who have used this procedure to access the pathologies in the mandible. The use of this technique for the removal of the tumors of the mandible had been tabulated in Table 1 with the details of the pathology which was addressed in the past using this technique.

\section{Conclusion}

This technique needs to be popularised for the excision of deeply seated pathology as there are minimal postoperative complications like mandibular discontinuity. This procedure requires plating and may require maxillomandibular fixation for 2 weeks which is one drawback. Still the advantages are far more than the temporary discomfort which is faced the patient postoperatively.

\section{References}

1. Rittersma J, van Gool A V. Surgical access to multicystic lesions, by sagittal splitting of the lower jaw. J Maxillofac Surg. 1979;7(C):246-50.

2. Blinder D, Peleg M, Talcher S. Surgical considerations in cases of large mandibular odontomas located in the mandibular angle. Int J Oral Maxillofac Surg. 1993;22(3):163-5.

3. Kontaxis KL, Steinbacher DM. Yale New Haven Hospital Oral and Maxillofacial Surgery SC. 2015;

4. Wong GB. Surgical management of a large, complex mandibular odontoma by unilateral sagittal split osteotomy. J Oral Maxillofac Surg [Internet]. 1989;47(2):179-82. Available from: http://www.sciencedirect.com/science/article/pii/S027823 9189801132

5. Casap N, Zeltser R, Abu-Tair J, Shteyer A. Removal of a Large Odontoma by Sagittal Split Osteotomy. J Oral Maxillofac Surg. 2006;64(12):1833-6.

6. Scolozzi P, Lombardi T, Jaques B. Le Fort I Type Osteotomy and Mandibular Sagittal Osteotomy as a Surgical Approach for Removal of Jaw Cysts. J Oral Maxillofac Surg. 2007;65(7):1419-26.

7. Jones TA, Garg T, Monaghan A. Removal of a deeply impacted mandibular third molar through a sagittal split 
ramous osteotomy approach. Br J Oral Maxillofac Surg. 2004;42(4):365-8.

8. Singh V, Bhagol A, Sharma B, Narwal A, Aryaa S.

Surgical access to large unilocular cystic lesion through a sagittal split ramus osteotomy. J Oral Maxillofac Surgery, Med Pathol. 2012;24(4):195-7.

9. Kwon YD, Ryu DM, Lee B, Kim YG, Oh JH. Separation of the buccal cortical plate for removal of the deeply impacted mandibular molars. Int J Oral Maxillofac Surg. 2006;35(2):180-2.

10. Wong GB. Treated by Sagittal Ramus Osteotomy and Peripheral Ostectomy. 1986;1221-4.

11. Silva de Oliveira JC, Garcia Jr. IR, de Melo WM, Barbosa S de M, Santos Rabelo Jr. PM, Bastos EG. Sagittal Mandibular Osteotomy for Removal of Intraosseous Lesion. J Craniofac Surg. 2014;25(3):E2379.

12. Mahmood L, Demian N, Weinstock YE, Weissferdt A. Mandibular nerve schwannoma resection using sagittal split ramus osteotomy. J Oral Maxillofac Surg. 2013;71(11):1861-72.

13. Orbach S. Ossifying fibroma of mandibular ramus treated with sagittal splitting osteotomy. N Y State Dent J [Internet]. 2008;74(6):34-6. Available from: http://ovidsp.ovid.com/ovidweb.cgi?T=JS\&PAGE=refere nce $\& D=$ med5 $\& N E W S=N \& A N=19195236$ 